\title{
How Entanglement Phenomenon Offers a conscious Universe
}

\author{
Mehrnaz Monzavi* \\ University of Canterbury, New Zealand
}

Submission: June 28, 2017; Published: July 06, 2017

*Corresponding author: Mehrnaz Monzavi, University of Canterbury, New Zealand, Tel: 006-422-471-7389;

Email: mehrnazmonzavi85@gmail.com

Abstract

In this paper, by the aid of entanglement phenomenon from modern physics, the existence of universal memory will be demonstrated. We focus on the argument based on memory in order to support our contention about a conscious universe. In this regard, the memory-like characteristics associated with the world is a step towards establishing the claim that the world manipulate consciously. Interestingly, there are numerous intellectual achievements following the results of entanglement theory in our social life that shows the fact that not only human society is not made of separated and solitary individuals but also human togetherness is effective and influential to the whole world. Therefore, the key point herein is the presence of a universal memory, which record any information from individuals and then afterwards, mutually sends the information back to us; thereby, due to the closely linked inseparable relationship between memory and consciousness, with existence of universal memory and application, usage or utilization from it, the world is necessarily conscious.One purpose of this study is to indicate that like a human as a live conscious existence has a memory, the world definitely does as well. And also, human is able to utilize from his memory, so the universe also is.

Keywords: Entanglement; Conscious universe; Universal memory; Collective consciousness

\section{Introduction}

The most basic definition for consciousness is simply awareness. In psychology, consciousness is generally used to describe a state of awareness. One common definition of consciousness that can be found in any dictionary is "the ability to be aware of and to be able to perceive the relationship between oneself and one's environment" [1]. It also seems to be associated with the ability to process, store and or act on information gathered from that external environment.

Based on the rational implications of philosophy, our job here is to elaborate the concept of consciousness step by step. The existence of memory alone is not sufficient to quickly establish the claim that the world has the attribute of consciousness. As a matter of fact, the ability to process the information is the definition of the consciousness. When there is utilization from memory such as recognition, making a choice, determining, etc. it is indicative of levels of consciousness; so the two important factors are memory and utilization from memory.

\section{Basic definition of memory}

A. The main notion of Memory is 'condensed information' that summarizes a large number of other pieces of information, all of which contributed to the formation of the memory. Therefore, the key definition of memory is the storage of the condensed information.

B. Numerous scholars asserts the "collective aspect of memory", which is derived from the "collectiveawareness or collective consciousness". Some scholars argue that these individual and collective memories mutually influence each other [2].

\section{'Entanglement' phenomenon in physics}

In a simple explanation, we consider two entangled photons or a pair of photon, one of those is sent to observer (A) and the second is sent to observer (B); the two observers could be in a notable distance apart. It should be mentioned that two entangled photons must have orthogonal polarizations; this is due to the law of the conservation of angular momentum: 'angular momentum of the system before the split must equal the angular momentum of the system after the split'. So when (A) measures the polarization of its photon and finds it to be, say (Figure 1), vertically polarized, we instantly know that (B)'s photon will have horizontal polarization even though (B) has not yet measured it [3]. 


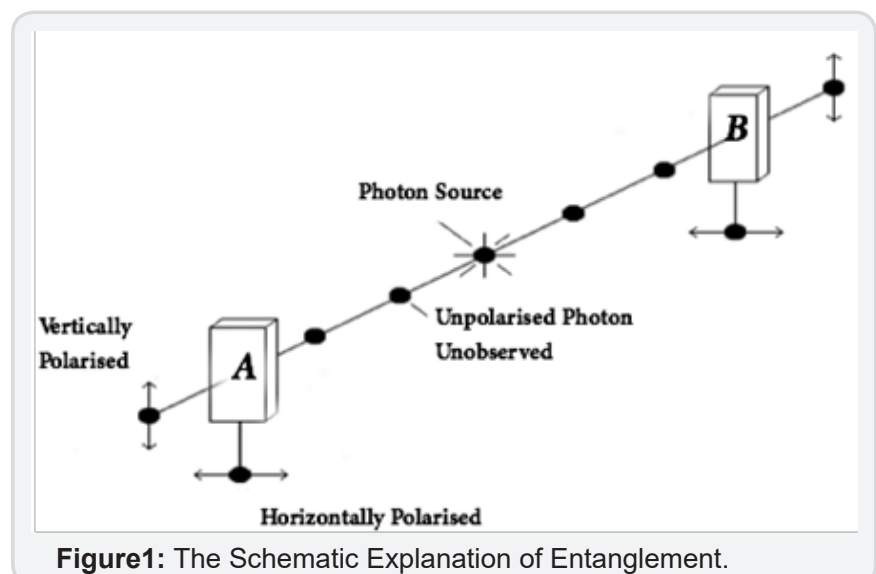

Figure1: The Schematic Explanation of Entanglement.

Looking deeply in the above brief description, the first result is that entanglement represents "characteristics of being remembered". Several scientists considered it as "teleportation" in which two or sometimes more entangled objects serve as a link that moves quantum information from one physical location to another [4]. Therefore, the setup is really simple; one object records the information to be teleported [5]. Nowadays several papers are published about the generalization of this subject. 'Everything is entangled' or the 'Entangled Universe' are the common topics; For example, in article everything is entangled (2012), due to the cosmological evolution, everything evolves into an entangled state and the entanglement easily can be considered beyond the cosmic horizon. However, we cannot observe this entanglement too easily because the entanglement is diluted so a randomly chosen pair of nearby objects is not inherit too much of this entanglement. Therefore, it extends to everything in our universe [6]. So the first result of this, is memory feature, but as we mentioned earlier, the actions of remembrance and recognition from the storage implies as though there is consciousness. In fact, the final result of entanglement is 'universal memory' and then after the existence of 'collective consciousness'. This is really similar with some theories in Psychology, Social Sciences and religion.

\section{Philosophical implications about universal consciousness}

Carl Jungpsychotherapist, who established analytical psychology, stated the concept of the collective unconscious as universal datum or universal library of human knowledge and wisdom [7]. Moreover, the theory of Noosphere by Vladimir Vernadsky introduces the same idea. Noosphere derived from Greek language: nous is mind and sphaira is sphere. It denotes the sphere of mind or thinking layer of the world. As the mental cover of our earth, the Noosphere defines mind and consciousness as a unitary phenomenon [8]. Hagelin Quantum Physicist explores the concept of "field of consciousness". With considering the empirical scientific frameworks, it indicates that the individual consciousness exists beyond our brain and physical body. In fact, it is shown that we human are not isolated individuals but more we are as a part of a collective consciousness, which can be considered as the outcome or result of the individual's consciousness [9]. In another terminology, it is named collective soul introduced by other thinkers in the field of sociology and philosophy. The consequence of all human feelings and perceptions is reflected in this collective soul and it implies the global population qualitative of developments. In fact, we can consider this as a memory like a big mirror or universal memory for consciousness, which record all individual's consciousness; when we humans pulse the radiations of our thoughts, insights, attitudes, beliefs and so on towards it, this memory after a while reflects the outcome of our thoughts to us. So it is given a fact that people are all connected to each other from the collective soul or collective consciousness; and the feedback of their thought, behaviors, attitudes, and so on is reflected back to them by the mirror of the collective soul [10]. The concept is truly showed in Figure 2.

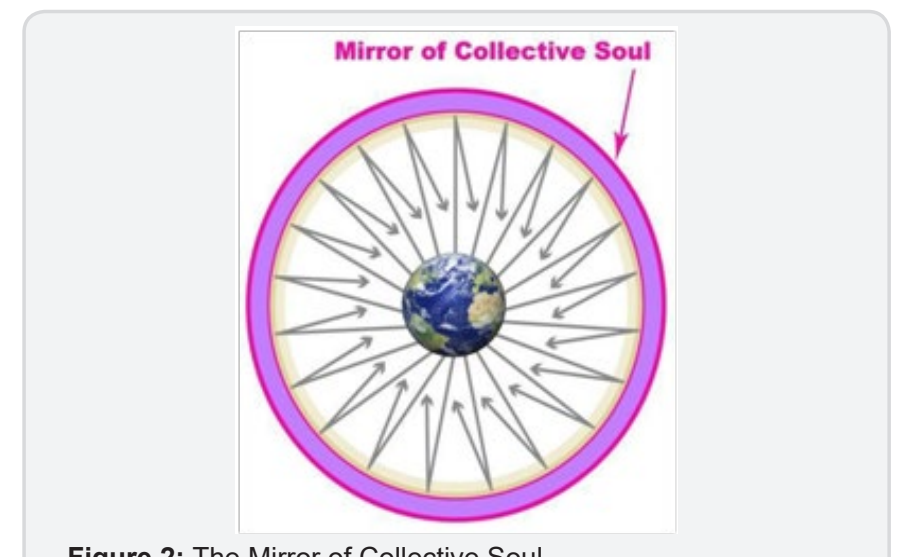

Figure 2: The Mirror of Collective Soul.

\section{Several instances of universal consciousness}

Morphic fields by rupert sheldrake: Sheldrake by conducting experimental researches considers the Morphic fields in all beings, even crystals, atoms, plants, birds and human societies.For example in the case of rats in the laboratory, when a number of them learned a new maze, other rats would also learn it easily and quickly elsewhere. Sheldrake explains the whole process by the definition of Morphic resonance. Another example is a fascinating experiment among English students. Sheldrake chooses three similar Japanese verses: one is a traditional famous lyric and the other is a very new contemporary verse and the last is nonsense pointless poems. Students were asked to memorize the poems while they were not aware of the contents. The result indicates that English students easily learned the famous Japanese poem. So we can find out that the famous poem was recorded in collective consciousness and the students were affected by that. In summary, when a critical number of people learn something new, the process of learning would become easier for those that would get involved with it after. It means that we humans are unconsciously linked and nurtured in a collective consciousness by considering a collective memory to store knowledge when utilization from the collective memory and reflection will be taken place [11]. 
Monkey case by ken keyes: The projection titled the hundredth monkey by Ken Keyes explains the collective consciousness as a result of an observational experiment. Some monkeys started to wash sweet potatoes before consuming. Other monkeys even in other islands learned the new behavior not from observation but from the spread of new behavior. This is an effect in which learned behavior of monkeys spreads instantaneously from one group of them to all others once their number is reached to a critical level. Its key notion is that when enough species in a society or group adopt a new behavior or learning, an ideological breakthrough occurs among them that lead this new awareness to be communicated directly from mind to mind without the linkage of external experience and all individuals in the society or group spontaneously adopt it. Keyes presented the monkey case effect phenomenon in order to discuss positive change in a human society [12].

Maharishi effect: Maharishi Mahesh Yogi, proposed a theory in transcendental meditation in 1960.He submitted his idea that if substantial population practices the transcendental meditation method, the quality of life for the whole population would change dramatically. He published his idea in 1976 about the decrease of the crime in the society. The result demonstrates that for $1 \%$ of the people practicing the meditation in a community, there is $16 \%$ decrease of crime in average. Later, this universal phenomenon was named "Maharishi effect" and expanded as a positive coherence in the field of TM and TM-Sidhi programs. Surprisingly, statistical analysis indicated around $11 \%$ decrease in violence at Washington and in total crimes at Metro Manila and Union Territory of Delhi. Another experiment was done in 1983 to test the Maharishi effect in Jerusalem. It was aimed to reduce the stress in the collective consciousness and behavior of people in Israel and Lebanon. The finding of this study demonstrated that for a large number of people for the Meditation group,the victims of war decreased by $76 \%$. It should be said that, this project were constantly repeated, for more than two years during the war [13].

Religious perspective: The importance of collective prayer can be determined herein in religious practices, such as allotting a day especially for global collective prayers. For example in Islam, Fridays are specified for congregational prayers because calling for congregational prayers are frequently mentioned in the holy Qur'an, which is the central religious text of Islam. People are mostly asked to gather at midday on Friday to perform a prayer as communion. Broadly speaking, such communities invocate universal peace, collective salvation, redemption and intercession. It is noted that there is a bigger reward in collective prayers as well as it could form mutual understanding and chain of love that leads to feeling of a collective unity. Besides, the value and power of collective prayers for seeking rain is also a means of providing religious lessons and spiritual advances in Islam because in several sections of Holy Qur'an is mentioned that the most merciful is God [14].
Similarly, in Christianity, Sunday is allocated for collective Orison and its central concept is about collective salvation. Such group invocations are performed for different purposes by considering social aspects of prayers, for example, to pray collectively for health as well objective conditions like for world peace [15]. Altogether, this indicates that human beings have a path, which is shared together and they are affected by this joint part. In Eastern tradition, Zen doctrine is likewise the expression of a general consciousness. According to the teachings of Zen, although individuals are separated and there is defined selfconsciousness for everyone, yet from a very broad point of view, taken together it is seen as a single universal consciousness. Two perspectives of consciousness are considered; first it is only about separate individuals and the second, in a broader scheme, is universal. In this perspective, it is very childish to see the world only from one limited point ofsentiment that establishes the world and its constituents just from one plaza. It means that from an all-encompassing view, separate individual consciousness are all related and it creates a higher one by extensions such as towards the consciousness of a school, ethnic groups, political parties as well as towards the city and country. In fact, what we see onthe Earth, good or bad as well as negative or positive are outcomes of humanity's actions that can harm or help, give out advantage or disadvantage toward the all [16].

\section{Conclusion}

In sum, our universe is able to act consciously to save information, process and then reflect. Considering the faculty of memory is possible from two sides: (i) one is the storage side and the (ii) is the utilization side. The second one truly demonstrates the features of conscious action; so, eventually, what quantum entanglement says is a consequence of Consciousness and then after, by gathering together empirical observations, we are able to conclude that our world is somehow functioning consciously.

\section{Reference}

1. Edgar D Mitchell, Robert Staretz (2011) The Quantum Hologram and the Nature of Consciousness. In: R Penrose, et al. (Eds.), Consciousness and the Universe, MA: Cosmology Science Publishers, Cambridge, USA, pp: 18-19.

2. Joël Candau (1998) Memoire et Identite, PUF, Paris, p. 225.

3. Gregg,Jaeger (2009) Entanglement, Information, and the Interpretation of Quantum Mechanics. Springer Verlag, Berlin Heidelberg, Germany, p. 321.

4. Rita L Atkinson, Richard C Atkinson, Edward E Smith, Daryl J Bem, Susan Nolen-Hoeksema (2000) Hilgard's introduction to psychology, Harcourt Brace College Publishers, USA, p. 768.

5. S Olmschenk, DN Matsukevich, P Maunz, D Hayes, LM Duan, et al. (2009) Quantum teleportation between distant matter qubits. Science 323(5913): 486-489.

6. Roman V Buniy, Stephen D H Hsu (2012) Everything is Entangled, Physics Letters B: Nuclear, Elementary Particle and High-Energy Physics 718(2): 233-236.

7. CG Jung (1981) Collected Works of C.G. Jung. Princeton University Press, USA, p. 1-18. 
8. Dvid Pitt, Pual R Samson, Mikhail S Gorbachev (1999) The Biosphere and Noosphere Reader: Global Environment, Society and Change. Routledge, UK, p. 222

9. John S Hagelin (1987) Is consciousness the unifed field? A field theorist's perspective. Modern sciences and Vedic Sciences 1(1): 2-60.

10. Mohhamad Ali Taheri (2008) Human from another outlook. Bijan Press, Iran, p. 285.

11. Sheldrake R (1981) A New Science of Life: The Hypothesis of Formative Causation. Jeremy P. Tarcher, Los Angeles, USA, p. 277.

12. Ken, Keyes (1984) The hundredth monkey, Devorss\& Co (Txp), USA p. 176.
13. Orme-Johnson DW, Alexander CN, Davies JL, Chandler HM, Larimore WE (1988) International Peace Project in the Middle East: The Effects of the Maharishi Technology of the Unified Field. Journal of Conflict Resolution 32(4): 776-812.

14. Nasr SH (2008) Islamic spirituality: foundations. Routledge, UK, p. 480.

15. Ferguson E (1993) Doctrines of human nature, sin, and salvation in the early church. Library of congress cataloging-in-Publication data.

16. Capra F (1999) The Tao of physics. Shambhala Publications, Boston Massachusetts, USA, p: 366. 